\title{
A Diversidade da Rede Terapêutica Alternativa no Rio de Janeiro ${ }^{1}$
}

\author{
FÁTIMA REGINA GOMES TAVARES
}

\section{RESUMO}

O objetivo do trabalho é discutir as diferentes concepções de práticas terapêuticas que emergem das noções difusas de cura holística e equilíbrio energético, características da terapêutica alternativa do tipo "nova era". São analisadas duas experiências terapêuticas singulares e contrastivas, que expressam a diferenciação interna do que designamos rede terapêutica alternativa. Os casos apresentados são indicativos das dificuldades em se proceder a uma delimitação rígida das fronteiras da terapêutica alternativa, assinalando os possíveis espaços de articulação entre o referencial da nova era e a cultura religiosa-terapêutica local.

Palavras-chave: Religião; movimento nova era; terapias alternativas. 
Os estudos sobre o movimento nova era no Brasil têm ressaltado, de perspectivas diversas, a importância que a dimensão terapêutica assume no âmbito desse fenômeno. Assim, os enfoques podem abarcar uma visão alargada da terapêutica e da cura, nos moldes de uma "obsessão pela cura", que é constitutiva do movimento (Soares, 1994; Amaral, 2000); podem considerá-la parte de um circuito mais amplo de novas redes de sociabilidade urbana, o circuito "neo-esô" (Magnani, 1999, 1999b); ou podem tratar a questão terapêutica no âmbito da sua especificidade em relação ao movimento "nova era" (Werdner Maluf, 1996; Tavares, 1998, 1999; Martins, 1999).

A diversidade de práticas que configuram a dinâmica desse movimento encontra-se diretamente relacionada ao grau de visibilidade que este vai adquirir no espaço urbano. Atividades transitórias, como encontros, workshops, feiras e vivências combinam-se com lugares mais estáveis de experimentação dessa espiritualidade. Dentre estes últimos, pode-se sugerir que os espaços alternativos - onde se oferecem diferentes práticas, acentuando-se, em maior ou menor grau, a dimensão terapêutica das mesmas configuram áreas de relativa estabilidade, contribuindo enormemente para a visibilidade do movimento, tanto entre os adeptos como para a sociedade mais ampla.

O objetivo deste trabalho é discutir as continuidades e descontinuidades de duas experiências terapêuticas - localizadas em espaços alternativos distintos - pertencentes ao que designamos por rede terapêutica alternativa, uma rede que apresenta relações mais ou menos próximas com a dimensão terapêutica característica do movimento "nova era"”.

Nesse sentido, pretendemos apontar a extensão da rede terapêutica alternativa em suas relações com as práticas mágico-esotéricas de cura holística, que constituem o núcleo duro da perspectiva "nova era"de cura ${ }^{4}$. São redes que mantêm relações de continuidade, mas que não se confundem inteiramente, compondo complexa dinâmica de afinidades e descontinuidades, delineando uma certa autonomia em relação aos princípios mais gerais da cosmologia do "errante" da nova era.

Por outro lado, também é necessário distinguir a especificidade dessa rede terapêutica alternativa (e da autodesignação dos profissionais que dela participam enquanto terapeutas), de outras terapêuticas alternativas, sejam elas inscritas em sistemas religiosos de cura (como a umbanda e o espiritismo) ou práticas terapêuticas oriundas da confluência de diferentes tradições populares, comumente reunidas sob a designação de medicina "popu- 
lar" ou "rústica"5. Embora esses circuitos não sejam estanques, havendo, em muitos casos, áreas de interpenetrações, a ascensão da rede terapêutica alternativa na última década vem conferindo a essa rede uma legitimidade social diferenciada em relação às outras terapêuticas alternativas ${ }^{6}$.

Dentre a variedade de espaços alternativos que existem na Região Metropolitana do Rio de Janeiro, tomamos como referência duas experiências distintas de gestão da prática terapêutica: a primeira, localizada na Zona Norte carioca e a segunda, em Niterói. Pretendemos mostrar, a partir dessas experiências, diferentes concepções da prática terapêutica que emergem do quadro mais geral de orientações dos terapeutas alternativos ${ }^{7}$. Distanciamonos da idéia, bastante difundida, aliás, de que esse referencial possa ser facilmente traduzido como uma nebulosa de bricolages resistentes a qualquer aproximação mais cuidadosa, compondo um território de "permissividades" utilitaristas por parte de seus praticantes, onde impera a ausência de qualquer critério interno relativo a procedimentos mais ou menos adequados, bem como de avaliações entre os profissionais aí implicados. Os casos a serem relatados configuram experiências singulares e contrastivas, apresentando critérios de proximidade e distanciamento mais ou menos explícitos e que podem ser indicadores da confecção de redes de legitimidade intragrupo.

\section{Primeiro Caso: o Instituto Solaris}

Num olhar mais apressado, percebe-se grande semelhança entre o Instituto Solaris - uma casa confortável situada no bairro da Tijuca ${ }^{8}$ - e os demais espaços alternativos espalhados pela cidade. Na disposição do espaço físico, a regra é a mesma: uma pequena sala de recepção e triagem da clientela onde, enquanto se espera a hora marcada da consulta, pode-se tomar contato - em cartazes fixados no mural ou ainda em pequenos jornais, periódicos ou não - com um conjunto extremamente variado de informações sobre cursos, palestras e workshops em andamento. No entanto, uma pequena diferença pode ser notada: o caráter seletivo das informações oferecidas à clientela, tanto no que diz respeito à natureza dos cursos quanto ao local de sua realização. O que é divulgado encontra-se estritamente relacionado às atividades oferecidas pelo instituto, sendo quase sempre realizado nas suas dependências. Com uma decoração acentuadamente econômica, nota-se a ausência de materiais e referências típicos dos consultórios de terapeutas holísticos, como cristais, pêndulos, incensos, quadros e pôsteres 
com motivos esotéricos, peculiares a esse tipo de atividade.

Surgido em 1975, no bairro de Santa Tereza, o Instituto Solaris possui uma história muito antiga, se comparado à maioria dos espaços alternativos. Naquela época, funcionava sob o nome de Centro da Quadrinidade, numa referência direta à matriz californiana: o Centro da Quadrinidade criado por Fischer e Bob Hoffman, em 1970, onde se divulgava uma nova terapia que, mais tarde, se tornaria conhecida como "processo Fischer-Hoffman".

O surgimento do Centro da Quadrinidade em Santa Tereza encontravase ligado à expansão das atividades da matriz para outros países, no qual o "grupo do Rio" desempenharia papel fundamental: cinco anos após o início das atividades do Centro da Quadrinidade da Califórnia, é no Rio de Janeiro que ele encontra seu primeiro eco para, posteriormente, expandir-se a outras regiões do Brasil, bem como a outros países ${ }^{10}$.

A concepção central da terapia psicológica situa-se na "estrutura da quadrinidade", que postula uma compreensão da natureza humana a partir da articulação de quatro dimensões interdependentes: o corpo (dimensão física); o intelecto (dimensão racional); a criança (dimensão emocional) e o ser espiritual (a essência do homem). O objetivo do trabalho terapêutico proposto reside numa re-harmonização dessas dimensões, de modo a recompor uma "unidade perdida", despedaçada ao longo do processo de socialização, especialmente da socialização primária.

O ponto de partida do trabalho inscreve-se no âmbito do conjunto de questões de ordem psicanalítica: o universo infantil, as relações imaginárias construídas em torno da imagem do pai e da mãe e os problemas decorrentes, no que diz respeito à construção da personalidade etc. São questões que, em função da sua natureza externa aos objetivos deste trabalho, não serão abordadas. Importa ressaltar o fato que, se o ponto de partida é de inspiração psicanalítica, o conjunto do trabalho terapêutico transcende os limites desse campo de saber. Através de uma ampla reorganização do universo discursivo do paciente (a detecção dos padrões negativos que geram sofrimento) e uma intensa mobilização da energia corporal (processos de catarse coletiva, além de outras terapias coadjuvantes), é que se desenrola o tratamento. A resolução possível dos problemas reside no reequilíbrio da desarmonia entre essas quatro dimensões. A dimensão espiritual, no entanto, é apresentada como o único ponto de observação seguro para a resolução dos conflitos e desarmonias internas.

O Centro da Quadrinidade surgiu no Rio de Janeiro após um contato direto com a experiência de trabalho que vinha sendo desenvolvida pela 
matriz californiana: um pequeno grupo de pedagogos e psicólogos cariocas deslocou-se para a Califórnia com o objetivo de se submeter à terapia, condição sem a qual não seria possível tornar-se professor da mesma.

A partir dessa experiência, formou-se no Rio o primeiro grupo de profissionais aptos a ministrar o "processo" fora da Califórnia e que se encontrava reunido no Centro da Quadrinidade, em Santa Tereza ${ }^{11}$. Entre os anos de 1975 e 1985, esse espaço alternativo aglutinou todos os profissionais que trabalhavam com o "processo", seguindo a mesma orientação inicialmente desenvolvida pela equipe de Hoffman. Em 1985, mudanças em relação à duração de certas etapas da terapia começaram a ser experimentadas pelos professores cariocas, pois as consideravam excessivamente longas ${ }^{12}$. Essas modificações, no entanto, não foram implementadas sem a prévia autorização de Hoffman. Seu aval era imprescindível, na medida em que todo o trabalho era por ele supervisionado. A legitimidade do grupo encontrava-se ancorada nesta premissa.

As modificações continuaram e não viriam do Rio de Janeiro, mas sim da própria matriz: a partir do sucesso, verificado por Hoffman, em relação à redução do tempo de realização da terapia, ele mesmo propõe, em 1986, uma modificação muito mais radical do que a do ano anterior. A estrutura foi inteiramente reformulada, permitindo que toda a terapia pudesse ser realizada em uma semana. Era o início do que se convencionou chamar de "processo intensivo", por oposição ao modelo anterior, "extensivo"13.

$\mathrm{Na}$ época da criação do processo intensivo, o Centro da Quadrinidade de Santa Tereza contava com 19 profissionais (em sua maioria psicólogos), todos envolvidos com a terapia. Dois desses profissionais deslocaram-se, então, para a Califórnia, a fim de realizar uma reciclagem nos moldes do novo modelo de processo. Após seu retorno e posterior treinamento de vários profissionais até então envolvidos com a versão extensiva, passariam a conviver no mesmo espaço - entre 1986 e 1988 - as duas formas de se ministrar a terapia, onde a opção por uma ou outra configurava uma escolha pessoal do terapeuta.

A convivência entre as duas formas de aplicação do processo parece ter tido reflexos diretos no grupo de profissionais de Santa Tereza. As divergências em torno das diferenças entre o "extensivo" e o "intensivo" introduziram disputas internas, o que levou a uma divisão do grupo inicial. Outro problema, de ordem econômica, acabou por acelerar o processo de dissolução do grupo: em 1988, o proprietário do imóvel onde funcionava o Centro da Quadrinidade conseguiu recuperá-lo, após longo processo de negociação 
na Justiça.

A partir de 1988, o grupo de Santa Tereza passou por um processo de atomização, com a criação de três novos espaços alternativos - Fênix, Zênite e Solaris - aglutinando os profissionais em torno da escolha da versão extensiva ou intensiva de aplicação da terapia. Os dois primeiros espaços passaram a trabalhar exclusivamente com o processo extensivo, enquanto o Solaris, após algum tempo de convivência com os dois modelos, especializouse na versão intensiva.

Durante todo o período que se seguiu, o processo intensivo passou a conquistar um número bem maior de adeptos no mercado terapêutico que a sua versão concorrente, permitindo uma continuidade de funcionamento do Instituto Solaris durante todo esse período, o que não se verificou em relação aos dois outros espaços alternativos.

O Instituto Solaris se apresenta atualmente como mais uma opção dentre as muitas oferecidas por toda a cidade. Algumas características, no entanto, distinguem-no dos demais. A primeira delas reside na temporalidade de uma experiência que se iniciou em 1975, com a qual o instituto reivindica uma relação de continuidade, a partir da detenção da autoridade de uma memória legítima (Hervieu-Léger, 1993) e que pode ser identificada em alguns fatores importantes, tais como: a coordenadora do Centro da Quadrinidade de Santa Tereza, principal responsável pela introdução dessa terapia no Brasil, continuou, durante quase todo o período de existência do Solaris (até os dias atuais), a coordenar as atividades no instituto; o próprio imóvel é fruto de uma doação da associação de ex-alunos do processo. Se considerarmos esta relação de continuidade com o Centro da Quadrinidade como uma experiência herdada pelo Solaris, perceberemos a sua antigüidade, embora o instituto, enquanto tal, possua uma história mais recente.

A segunda característica, decorrente da anterior, reside no fato de que a identidade (e a sua história) desse espaço alternativo encontra-se imiscuída na própria história da terapia que ele oferece, embora exista todo um esforço, por parte dos terapeutas do Solaris ${ }^{14}$, em distinguir as duas coisas. Entre os adeptos desse mercado terapêutico e, mais precisamente, os que já fizeram o processo Fischer-Hoffman, a associação entre a terapia e o instituto é quase inevitável. No entanto, ela não constitui a única atividade oferecida. Pelo contrário: da mesma forma que os demais espaços existentes no Rio, o Solaris oferece uma gama bastante variada de terapias, algumas delas já relativamente conhecidas, como o eneagrama e os florais de Bach; bem como cursos e workshops. A singularidade desse espaço em relação aos 
demais parece, portanto, residir menos no leque de recursos terapêuticos do que na forma como estes são apresentados à sua clientela.

Enfatizando sua vocação terapêutica, queremos acentuar o caráter fechado desse instituto em relação aos demais espaços alternativos, no que diz respeito à absorção de profissionais habilitados a trabalhar em suas dependências. Os critérios de entrada são rigorosos e explicitamente valorizados pelo seu corpo de profissionais. Caracterizando-se como um caso-limite, o Instituto Solaris realiza não somente uma rigorosa seleção profissional, preocupando-se com a seriedade e a competência, mas também uma seleção antecipada das atividades consideradas indesejáveis ou não adequadas ao seu perfil.

Quando perguntada sobre os critérios de entrada dos profissionais no espaço, a coordenadora assim respondeu:

"Tem que fazer um trabalho decente (...) primeiro, uma entrevista com a gente, comigo ou com a Vera [que são as coordenadoras]. A gente avalia o grau de intenção... a gente avalia o que pode avaliar. Aí, experimenta o trabalho, vê as bases do trabalho, não só em uma pessoa, faz em mais de uma. [mas aceita-se qualquer trabalho?] Por exemplo: nós somos muito procurados pra... astróloga, tarô... (...) mesmo que seja uma pessoa séria, é muito fácil confundir as coisas, mesmo astrologia. Por que não veio ainda uma pessoa de astrologia que... pra cá, nos procurar pra se juntar, levando a astrologia como uma ciência, né? Por exemplo, veio. Vieram algumas pessoas, mas a última foi uma moça com uma pedra de rubi pendurada aqui [no chamado "terceiro olho"] pra fazer astrologia. Nem pensar. (...) pode ser uma excelente astróloga, mas uma pedrinha aqui ou quadrinho aqui, cheio de não sei o quê... não. Vamos ter limite nessa história. (...) A gente tá querendo muito tirar os mitos. Então, quando fica muito... aí a gente corta”.

Entre os terapeutas desse espaço parece existir uma postura extremamente vigilante no que concerne a uma possível "contaminação" por profissionais mal-qualificados e pouco sérios. A própria concepção de pertencimento ao mercado da terapêutica alternativa - veiculada pela clientela mais recente - é rechaçada entre seus profissionais, para quem qualquer tentativa de comparação com a forma como se desenvolvem as práticas alternativas em geral passa a ser vista como problemática. A percepção da atual profusão de técnicas terapêuticas é muito questionada entre esses profissionais, como podemos observar no relato da mesma terapeuta: 
"Eu acredito que proliferaram muito essas terapias e cada uma é mais... às vezes é a mesma coisa, mas muda o nome, pra atrair, às vezes faz um detalhezinho, pra chamar, né? Por que a nossa sociedade aí, a sociedade ocidental, cultiva muito a rapidez, o novo, né? (...) Então, o novo, o rápido, e aquele que só eu fiz. Então, é... antigamente, algum tempo atrás, era mais ou menos assim. Isso sempre existiu, mas em nível de terapia, tá existindo de uns anos pra cá. (...) Hoje é o maior status fazer uma terapia estranha, diferente... e terapia que não mexa com pai e mãe, terapia que não mexa com base. Eu já ouvi muito essa história assim: quê? Você ainda trabalha com coisa de infância, pá rá rá... Isso já era. Eu já ouvi. De pessoas comuns e de terapeutas. (...) Eu vejo assim: 'Vamos ver se isso tá dando certo?' Muito instrumentalismo. (...) As terapias alternativas abriram muito pra quem não é da área. Pessoas que não têm formação nenhuma, noção nenhuma. Então, quer dizer, aí você abriu pro comércio, abriu pra ganhar dinheiro, abriu pra fazer um curso de final de semana pra sair já sendo terapeuta com outros fins. Então, eu acho que a terapia alternativa tá sem nenhum critério de licenciatura. Não é que seja só o profissional médico, mas tem também... precisaria de algum critério, né? Pra ser alinhado. Eu acho que o problema tá aí, não é o fato de existirem terapias alternativas. (...) O número de profissionais competentes é minoria no mercado. Existem pessoas mal formadas ou totalmente desinformadas (...) tem pessoas que estão muito inocentes e ingênuas. Inflacionou mesmo. Eu acho que daqui a um tempinho, como tudo, vai esvaziar".

\section{Segundo Caso: a Fundação de Fitoterapia Maria Conceição Pereira da Costa}

Mais conhecido como Instituto Dona Conceição, a sua prática terapêutica encontra-se centrada na fitoterapia. Ele em nada se assemelha aos demais espaços alternativos que podemos encontrar na cidade: as instalações físicas, a forma de administrar a terapêutica, a expectativa da clientela.

Todos aqueles que se deslocam até Piratininga - uma região de acesso relativamente difícil, distante do Centro de Niterói - possuem um firme propósito: adquirir as "gotinhas milagrosas" cuidadosamente preparadas por dona Conceição. Apesar de o instituto realizar vários tipos de tratamento fitoterápico, através de pomadas e chás medicinais, o carro-chefe do trabalho é a administração das "gotinhas milagrosas". Elas atuam na cura de 
todos os males, desde os mais corriqueiros e banais, de fácil tratamento pela medicina, até os casos mais graves, como câncer, problemas cardíacos e circulatórios etc. A lista é vasta e os casos de cura também, relatados por adeptos de todas as classes sociais e idades. A fórmula utilizada na composição do medicamento é a mesma em todos os casos, variando somente a dosagem, que se coaduna à gravidade da doença e ao seu estágio de evolução.

A despeito da fama de milagroso que é freqüentemente atribuída ao poder curativo das "gotinhas", tanto dona Conceição como seu filho - que divide com ela a tarefa do atendimento ao público - procuram enfatizar a natureza fitoterápica do medicamento como razão fundamental da eficácia do tratamento ${ }^{15}$.

Por outro lado, embora a razão fundamental da eficácia do tratamento resida em sua dimensão fitoterápica, ela não é a única. $\mathrm{Na}$ fala desses terapeutas, a dimensão mais objetiva do princípio ativo contido na "gotinhas" imiscui-se ao aspecto mais difuso da crença ou fé, que deve comparecer, embora de forma secundária, como coadjuvante na obtenção da cura. Assim, a crença no sucesso do tratamento auxilia na própria obtenção da cura, mas de forma alguma ela é tida como condição sine qua non para o seu sucesso. A necessidade de se acreditar no tratamento comparece como uma atitude de auxílio e mobilização da energia do próprio paciente para a obtenção da cura.

Nesse sentido, as "gotinhas" da dona Conceição possuem uma eficácia que se encontra desvinculada - autônoma - da crença. Elas funcionam como catalisadoras de um reequilíbrio lento e sutil através da reorientação das energias, proporcionando uma limpeza do corpo físico. Com base nessa orientação mais geral, pode-ser compreender a sua ação, bem como a veiculação da mesma fórmula para um conjunto extremamente variado de doenças.

A ação catalisadora das "gotinhas" é fruto da articulação de três dimensões distintas e indissociáveis. A primeira é o princípio ativo contido nas ervas que compõem a fórmula, caracterizando o seu aspecto mais denso, facilmente identificável através de análises químicas. O segundo diz respeito ao princípio de acumulação de energia, presente na própria composição das plantas empregadas: é um aspecto mais sutil do que o primeiro e se fundamenta na premissa de que determinadas plantas apresentam o potencial de acumular energia externa. Por fim, o último aspecto reside na própria dimensão catalisadora que envolve a pessoa da dona Conceição: no momento em 
que manipula os diferentes componentes, ela transmite sua energia pessoal para o remédio, ou seja, ela também faz parte da própria medicação que ela confecciona e distribui. A especificidade deste último aspecto torna o remédio uma criação pessoal e intransferível, sendo impraticável a sua comercialização em escala industrial.

Para dona Conceição e seu filho, não somente existe uma explicação logicamente articulada para o sucesso das "gotinhas" no âmbito da variedade de doenças possíveis, como também o próprio tratamento deve ser cercado de cuidado e observâncias de caráter estritamente operacional ${ }^{16}$. Segundo dona Conceição, somente através de uma correta administração do medicamento é que o paciente poderá obter uma melhora crescente e alcançar a cura. É um tratamento de duração muito variável, que depende do estado geral do paciente e do grau de instalação da doença no organismo. A ocorrência de alguns sinais orgânicos, no entanto, costuma indicar um movimento de reversão do quadro patológico. Embora dolorosos e de difícil aceitação para o paciente, esses sinais vêm indicar que o processo de cura se encontra em andamento, na forma de um expurgo da doença pelo organismo.

Aliada ao tratamento das "gotinhas", existe também uma série de observações adicionais que são freqüentemente abordadas por dona Conceição. Estas compreendem alguns cuidados com a alimentação (que deve ser a mais natural e equilibrada possível) e a modificação de hábitos que propiciam uma melhora da qualidade de vida, tanto do ponto de vista físico (não fumar, não beber, etc.), como ético e moral. Tanto o processo de instauração da doença como o da cura são compreendidos como alusões metafóricas de um conjunto muito mais amplo de predisposições construídas pelo indivíduo ao longo de sua vida

Embora o paciente receba as "gotinhas" gratuitamente ${ }^{17}$, quando da sua primeira visita à instituição, ele costuma pagar uma taxa única (mediante a qual ele recebe a ficha de inscrição) que permitirá seu acesso ao tratamento pelo tempo que for necessário. Embora o valor cobrado seja relativamente baixo, acessível à maioria dos pacientes que freqüentam a instituição, a existência dessa taxação, ainda que praticamente simbólica, causa desconforto tanto por parte de dona Conceição como entre os pacientes. O curioso é que a maior parte das críticas que são feitas em relação à cobrança parece direcionada para a constatação de um certo desvirtuamento do objetivo filantrópico do trabalho.

Essa dimensão desinteressada constitui um ponto fundamental para a 
identidade do trabalho da fundação. Segundo o filho de dona Conceição, o trabalho vem sendo realizado há mais de 20 anos, com dotação própria e com donativos voluntários, sendo que até os dias atuais não conta com o apoio de nenhuma outra instituição pública ou privada. Apesar das constantes dificuldades financeiras que ameaçam a continuidade da fundação, dona Conceição sempre enfatiza a preocupação em não distorcer o objetivo de assistência gratuita do trabalho. Ao longo de sua trajetória, muitos foram os problemas decorrentes de interpretações pejorativas do seu trabalho, que recorrentemente a acusam de "sensacionalista" e "charlatã".

Se verificarmos a radicalidade da sua proposta, não é de toda sem fundamento sua preocupação com relação à receptividade do seu trabalho. Os embates travados com a medicina oficial têm sido constantes, embora atualmente eles sejam um pouco menos intensos do que nos anos 80, quando dona Conceição alcançou fama na grande imprensa.

Data dessa época a veiculação de reportagens sensacionalistas publicadas nos jornais $O$ Globo e Tribuna da Imprensa - que giravam em torno da imagem metaforizada de "Mãe Conceição", imagem rejeitada com veemência por ela, pela sua alusão valorativa a um conjunto de signos e referências de cunho religioso da qual não partilhava. Assim, segundo nos relatou seu filho, o "caráter difamatório dos noticiários" decorria do desconhecimento de que a eficácia do trabalho guardava autonomia em relação a qualquer referência de cunho religioso.

De qualquer forma, e embora ela sempre tenha procurado manter uma postura de distanciamento em relação a qualquer cosmologia religiosa, muitas vezes enfrentou a ortodoxia terapêutica, que insiste em desqualificá-la como "pseudomilagreira".

Por outro lado, o quadro de agressividades e incompreensões mútuas entre os médicos e dona Conceição - não deixa de ter a sua razão de ser: a terapêutica apresentada por dona Conceição para o tratamento de inúmeras moléstias - sobretudo o câncer - pode ser encarada como uma contraofensiva ao tratamento quimioterápico e radioterápico convenciona ${ }^{18}$.

Muito pelo contrário, a proposta de tratamento veiculada na fundação se apresenta como uma alternativa explícita e que contrasta com a terapêutica oficial, embora mantenha com esta mesma ortodoxia uma relação tensionadamente ambígua. O tratamento baseado nas "gotinhas" é apenas um dos elos da corrente: existe toda uma concepção sobre a doença, bem como sobre a forma adequada de combatê-la.

Dona Conceição, em suas palestras, não se cansa de alertar para o fato 
de que a eficácia do tratamento é inversamente proporcional aos procedimentos a que são submetidos os doentes na terapêutica oficial. Em outras palavras: quanto menor for o grau de "invasão" da doença, maiores serão as chances de cura. Freqüentemente, ela aconselha os pacientes a não se submeterem a intervenção cirúrgica e nem a prosseguirem com qualquer tratamento adicional, seja ele quimioterápico ou radioterápico. Não deixa de ser impressionante a firmeza com que emite tais opiniões acerca da inviabilidade desses tratamentos, evidenciando uma certeza inabalável nas suas convicções, que foram construídas não somente a partir do momento inspirador de sua "revelação"19 mas, principalmente, por uma experiência de 20 anos de tratamento com as "gotinhas". A afirmação de que o tratamento oferecido pela medicina oficial é ineficaz, além de ousada, vem acompanhada de uma clara consciência do senso de responsabilidade para com as conseqüências dessa posição. Uma responsabilidade que, segundo ela afirma, foi lentamente construída ao longo de uma experiência que incorporava constantes avaliações em torno da eficácia do tratamento.

Se a administração das "gotinhas" abre um espaço de conflitos com a terapêutica oficial, o cotidiano do trabalho de atendimento aos doentes deixa espaços entreabertos, revelando ambigüidades e estratégias na defesa do trabalho realizado, protegendo-o de acusações que giram em torno do exercício ilegal da medicina. Não configurando exatamente uma concessão, mas aproximando-se de uma estratégia deliberada de convivência, um importante vínculo estabelecido com a medicina oficial é a requisição do diagnóstico da doença devidamente assinado por um médico. Constituindo uma exigência obrigatória para a aquisição das "gotinhas", o laudo médico é, segundo dona Conceição, a garantia contra possíveis acusações de "charlatanismo"20.

\section{Algumas Questões Comparativas}

Experiências terapêuticas tão distintas não foram recolhidas ao acaso: além de oferecerem a oportunidade de uma melhor visualização da diversidade da gestão terapêutica no âmbito do conjunto de orientações holísticas, partilhadas pelos profissionais da rede terapêutica alternativa, essas experiências particulares vêm compor as possibilidades-limite do amplo espectro que procuramos analisar.

A rede terapêutica alternativa apresenta uma diversidade de práticas que se encontram situadas numa região fronteiriça entre duas possibilidades distintas: de um lado, a gestão religiosa da cura e as práticas da medicina 
popular e, de outro, a medicina "oficial". A dinâmica que caracteriza essa rede articula uma relativa homogeneidade discursiva, com possibilidades diversas de elaboração das práticas que compõem esse espectro.

Os dois casos apresentados, ao mesmo tempo em que contrastam com a maioria dos espaços alternativos que compõem a rede, situam-se em cada uma das suas tênues fronteiras. O primeiro caso, do Instituto Solaris, ocupa um dos extremos, na medida em que se distingue dos demais espaços alternativos. Veiculando uma proposta de trabalho que tende a se distanciar da forma como a questão terapêutica (nos moldes de um mercado) vem-se desenvolvendo no âmbito da rede e apresentando critérios rígidos de entrada dos profissionais, esse instituto apresenta um grau máximo de "fechamento", que contrasta com a dinâmica de circulação característica dos demais espaços.

Constituindo o carro-chefe desse espaço, o processo Fischer-Hoffman apresenta um grau de ortodoxia que se distingue das técnicas e práticas terapêuticas veiculadas na rede. Trata-se de uma terapia psicológica (ainda que ancorada em um referencial espiritual) ministrada em vários países, sob a coordenação do seu fundador, na qual qualquer proposta de mudança só pode ser feita mediante sua autorização prévia. A própria formação dos professores dessa terapia é feita em centros especializados, sob a supervisão de profissionais devidamente habilitados para esse fim. Os professores que têm desenvolvido essa terapia seguiram um mesmo procedimento terapêutico, que é detalhadamente apresentado no "Guia do Professor", desenvolvido pela matriz californiana.

A centralidade que o processo adquire no âmbito das atividades desenvolvidas no Instituto Solaris é indicativa das reservas dos seus profissionais em relação ao caráter difuso implicado nas designações de "holístico" e "energético", para qualificação positiva dos procedimentos terapêuticos alternativos à medicina oficial. Embora várias terapias alternativas já relativamente tradicionais nesse mercado também ali tenham lugar, percebe-se uma constante vigilância e preocupação em relação ao esgarçamento da designação do termo "alternativo".

O trabalho desenvolvido por dona Conceição se situa na outra extremidade do extenso espectro de práticas terapêuticas. Tangenciando o universo da medicina popular e da gestão religiosa da cura, dona Conceição apresenta um inegável carisma, que se articula ao tratamento ali realizado. Numa observação mais superficial de seu trabalho, tem-se a impressão de que a importância da sua figura orienta todo o processo de cura, mas na medida 
em que mergulhamos nesse universo, outros componentes ganham relevância e apontam para a objetividade das "gotinhas", em detrimento da crença nos poderes extraordinários da sua pessoa.

O mecanismo de atuação do remédio se coaduna com as representações mais gerais verificadas no âmbito da rede terapêutica alternativa, como podemos verificar no relato de seu filho:

"O remédio, ele vai equilibrar, vai energizar o seu organismo. Porque justamente o desequilíbrio causa uma mudança de freqüência. Quando ocorre essa mudança de freqüência, então já dessintonizou do cérebro. É... agora é por conta própria. É um tipo de reação atômica, entendeu? Aquele átomo começa a vibrar, vai, vai pulando de camada e vai embora. Então, o que esse remédio faz? O remédio, ele equilibra o organismo e energiza o organismo do paciente. Então, ele não mata a célula cancerosa. O que ele faz... ele equilibra, energizando, e o próprio organismo vai se livrar da doença. É assim o funcionamento, é assim que a gente tem conseguido as curas”.

Como podemos observar, a explicação para a eficácia do medicamento incorpora todos os referenciais comuns aos demais terapeutas. As categorias de energia, equilíbrio-desequilíbrio e freqüência-vibração comparecem como referências centrais na explicação da eficácia do medicamento. A compreensão da dimensão catalisadora das gotinhas que vão habilitar o organismo a recompor seu próprio equilíbrio natural (na forma de uma "autocura") indica as semelhanças que percorrem as diferentes práticas terapêuticas. A intervenção carismática de dona Conceição se dá no próprio processo de fabricação do medicamento, encontrando-se, portanto, incorporado a ele - uma vez materializado em cada "gotinha", estas adquirem uma eficácia autônoma em relação à sua vontade. A correta administração do medicamento, aliada a um esforço pessoal do paciente, são fatores centrais para a obtenção da cura. Verifica-se aqui uma ambivalência entre a dimensão milagrosa das gotinhas e sua formulação medicamentosa: embora incorporem o poder curativo de dona Conceição, elas possuem uma ação independente da sua vontade e da do paciente.

Os dois exemplos apresentados, na medida em que constituem tiposlimite, são indicativos das dificuldades em se proceder a uma delimitação rígida das fronteiras da rede. De um lado, o Instituto Solaris, que apresenta todas as características de um espaço alternativo, mas que manifesta profunda tensão na sua identificação enquanto tal, procurando se distanciar de uma possível rotulação como "mais um dentre os demais". Nesse sentido, 
poderíamos dizer que o Solaris aparenta ser mais "alternativo"21 do que efetivamente pretende ser. De outro, a Fundação Fitoterápica Dona Conceição, que procura se distanciar da imagem de que ali se operam curas milagrosas, através da ênfase na autonomia da eficácia do medicamento fitoterápico por ela produzido. Contrastando com o perfil do Solaris, a experiência da dona Conceição se revela muito mais alternativa do que aparenta.

Essas duas experiências, no entanto, possuem um ponto em comum, que as afastam da maioria das práticas terapêuticas da rede. Complexificam a discussão em torno dos critérios de construção da legitimidade social dessa rede, que advêm, principalmente, da crença na eficácia intrínseca do procedimento terapêutico utilizado. Esses são critérios que promovem a delimitação de fronteiras entre esses profissionais e os outros, sejam eles médicos ou chefes de terreiro, curadores ou benzedeiras.

Pois bem: é curioso observar que terapêuticas tão controladas em relação a possíveis desvios, como o processo Fischer-Hoffman e as "gotinhas" da dona Conceição, fundamentem na revelação a sua explicação de origem. $\mathrm{O}$ seu fundamento carismático comum, no entanto, teve diferentes desdobramentos quanto à sua possível rotinização.

Ambos os fundadores encontram-se vivos e mantêm-se controlando suas respectivas terapias, mas manifestam atitudes diferentes no que diz respeito à continuidade de seu trabalho. Enquanto Bob Hoffman transfere a outros a administração da terapia, procurando assegurar a sua pureza, através do controle do método e de sua ortodoxia, a continuidade do trabalho de dona Conceição só pode ser feita mediante uma "transferência de carisma", um processo que foge ao seu próprio controle e para o qual ela própria não tem expectativas.

\section{Referências Bibliográficas}

AMARAL, L. Carnaval da alma: comunidade, essência e sincretismo na nova era. Petrópolis: Vozes, 2000.

CANESQUI, A. M. Notas sobre a produção acadêmica de antropologia e saúde na década de 80. In: ALVES, P. C.; MINAYO, M. C. S. (Orgs.). Saúde e doença: um olhar antropológico. Rio de Janeiro: FIOCRUZ, 1998. 
HERVIEU-LÉGER, D. La réligion pour mémoire. Paris: Les Éditions du Cerf, 1993.

LOYOLA, M. A. Médicos e curandeiros. Conflito social e saúde. São Paulo: Difel, 1984.

LUZ, M. T. Cultura contemporânea e medicinas alternativas: novos paradigmas em saúde no fim do século XX. PHYSIS - Revista de Saúde Coletiva. Rio de Janeiro, v. 7, n. 1, p. 13-43, 1997.

MAGNANI, J. G. C. O circuito neo-esotérico na cidade de São Paulo. In: CAROZZI, M. J. (Org.). A nova era no Mercosul. Petrópolis: Vozes, 1999. . Mystica urbe: um estudo antropológico sobre o circuito neoesotérico na metrópole. São Paulo: Studio Nobel, 1999(b).

MARTINS, P. H. As terapias alternativas e a libertação dos corpos. In: CAROZZI, M. J. (Org.). A nova era no Mercosul. Petrópolis: Vozes, 1999. MONTERO, P. Da doença à desordem: a magia na umbanda. Rio de Janeiro: Graal, 1985.

RABELO, M. C. Religião, ritual e cura. In: ALVES, P. C.; MINAYO, M. C. S. (Org.). Saúde e doença: um olhar antropológico. Rio de Janeiro: FIOCRUZ, 1998.

RABELO, M. C. et al. Comparando experiências de aflição e tratamento no candomblé, pentecostalismo e espiritismo. Trabalho apresentado no XXI Encontro Anual da ANPOCS, Caxambu, 27-31 de outubro, 1998.

SOARES, L. E. Religioso por natureza: cultura alternativa e misticismo ecológico no Brasil. In: SOARES, L. E. O rigor da indisciplina. Rio de Janeiro: Relume-Dumará, 1994.

TAVARES, F. R. G. Alquimias da cura: um estudo sobre a rede terapêutica alternativa no Rio de Janeiro. Tese (Doutorado em Antropologia) - PPGSA / IFCS, Universidade Federal do Rio de Janeiro, 1998.

. O 'holismo terapêutico' no âmbito do movimento "nova era" no

Rio de Janeiro. In: CAROZZI, M. J. (Org.). A nova era no Mercosul. Petrópolis: Vozes, 1999.

Ascensão e profissionalização da terapêutica alternativa no Rio

de Janeiro (anos 80-90). PHYSIS - Revista de Saúde Coletiva. Rio de Janeiro, v. 9, n. 2, p. 75-98, 1999.

PESSANHA, D. As "curas milagrosas" e a idealização da ordem popular. Niterói: UFF/CEUFF, 1984.

RUSSO, J. O corpo contra a palavra. Tese (Doutorado em Antropologia Social) - PPGAS / Museu Nacional, Universidade Federal do Rio de Janeiro, 1991. 


\begin{abstract}
WERDNER MALUF, S. Les enfants du verseau au pays des terreiros. Les cultures thérapeutiques et spirituelles alternatives au sud du Brésil. Thèse (Doctorat en Anthropologie Sociale et Ethnologie). EHESS, Paris,1996.
\end{abstract}

\title{
NOTAS
}

1 Uma primeira versão deste trabalho foi apresentada no VII Encontro de Antropólogos NorteNordeste (ABANNE), no GT Religiões Brasileiras e Novos Aportes Teóricos e Metodológicos. Recife, novembro de 2001.

2 Doutora em Sociologia pelo PPGSA / UFRJ. Professora do Programa de Pós-graduação em Ciência da Religião da UFJF.

$3 \mathrm{O}$ delineamento da rede terapêutica alternativa no Rio de Janeiro foi objeto da nossa tese de doutoramento. No trabalho, argumentamos que os critérios de legitimidade que orientam a constituição dos terapeutas alternativos vêm promovendo uma certa "autonomização" dessa rede em relação ao referencial holístico, característico da espiritualidade "nova era" Esses terapeutas vêm redefinindo essa espiritualidade, na medida em que a situam nos parâmetros de uma "eficácia" propriamente terapêutica, compondo, assim, o que chamamos de "espiritualidade terapêutica" (cf. Tavares, 1998).

4 Amaral aponta a centralidade que o referencial mágico assume no âmbito da espiritualidade nova era, onde se entrecruza duas grandes "chaves" interpretativas: os pares energia-poder (hard) e espiritualidade-harmonia (soft). Para uma caracterização das práticas que configuram esse núcleo duro, ver, Amaral (2000). Para uma discussão do referencial cosmológico que norteia a rede terapêutica alternativa em suas aproximações e distanciamentos em relação à espiritualidade nova era, ver Tavares (1999).

5 Os estudos sobre as relações entre religião e terapêutica vêm-se intensificando no Brasil. Embora constituam uma temática "clássica" no âmbito da tradição antropológica, somente na década de 80 é que esse campo de estudos ganha uma atenção mais sistemática dos pesquisadores, através, principalmente, da incorporação de novos paradigmas de análise que vão romper com velhas dicotomias, como tradicional-moderno, lógico-ilógico e sagradoprofano. Cf. Canesqui (1998). Já dentro desse novo contexto de pluralidade de orientações, vários estudos têm procurado situar as relações entre a medicina "oficial", as "terapêuticas religiosas" e "medicina popular". Ver, dentre outros, Pessanha (1984); Loyola (1984); Montero (1985). Para uma discussão das práticas de cura no âmbito da performance ritual e das redes sociais que o sustentam, ver Rabelo (1998) e Rabelo et al. (1998).

6 Sobre a ascensão das terapêuticas alternativas em sua relação com a crise da racionalidade médica hegemônica, ver Luz (1997).

7 Esse quadro compreende quatro referenciais básicos: holismo como referência difusa; energia como explicação da dinâmica inerente ao par desequilíbrio-reequilíbrio; vibração, como operacionalizadora da dinâmica do fluxo energético; por fim, a terapêutica, que articula todas as demais categorias, adjetivando-as na forma de um "bem", de um "valor". Cf. Tavares (1999). 
8 Até 1997, a sede desse espaço situava no bairro da Tijuca. A partir de 1997, no entanto, o Solaris mudou-se para Botafogo e, após uma cisão do grupo de terapeutas, acabou retornando à Tijuca. A experiência que apresentamos aqui recupera a trajetória desse espaço até 1997, não incorporando as mudanças e as possíves alterações dela decorrentes.

9 O surgimento dessa terapia se situa, historicamente, no mesmo contexto de profusão terapêutica do final dos anos 60 e início dos 70 , exatamente na região considerada o berço dos "novos movimentos religiosos" e que foram objeto de uma literatura abundante sobre o tema. Embora nosso objetivo aqui não seja retraçar o panorama das questões presentes na época, não se deve perder de vista, no entanto, o contexto no qual se situa o surgimento dessa terapia, o universo de questões com o qual ela está - direta ou indiretamente - dialogando.

10 Até 1996 esta terapia era desenvolvida em onze países. No Brasil, existe no Rio, em São Paulo e Belo Horizonte de forma sistemática, ou seja, com sede própria e contando com um grupo de terapeutas qualificados. Na Argentina, as primeiras experiências datam do final de 1995, não tendo se constituído ainda um grupo de terapeutas próprio. Todos os demais países onde existe essa terapia se situam na Europa. Há um livro, traduzido para o português, de autoria de Bob Hoffman, intitulado O Processo da Quadrinidade, que expõe a origem e as várias etapas da terapia.

11 O processo Fischer-Hoffman foi levado para Belo Horizonte um ano após seu início, no Rio de Janeiro. Em 1979 ele começou a ser ministrado em Campinas e, em 1980, em São Paulo.

$12 \mathrm{O}$ tempo total de duração da terapia, tal como ela foi formulada inicialmente, girava em torno de três meses. A partir das modificações implementadas em 1985 pelo "grupo do Rio", passou a ser necessário um mês de meio de terapia.

13 A questão que se encontrava implicada nessa primeira modificação realizada no Rio e posteriormente na criação do "processo intensivo" não era uma diminuição ou exclusão de etapas terapêuticas, apontando para uma possível alteração da estrutura inicial, elaborada por Hoffman e sua equipe. O objetivo das mudanças era outro: "enxugar os excessos", utilizando "técnicas mais sutis" que buscavam uma intensificação emocional das etapas fundamentais do trabalho. Neste sentido, um curto espaço de tempo agiria a favor, diminuindo possíveis "resistências" do aluno.

14 Nem todos os profissionais que trabalham nesse espaço são professores do processo Hoffman. Esses profissionais costumam ministrar cursos e vivências, e mesmo oferecer técnicas terapêuticas para um público que, em sua grande maioria, já passou pelo "processo".

15 Tanto dona Conceição como seu filho se referem às gotinhas como remédio ou medicamento, enfatizando, assim, o caráter material do seu efeito curativo.

16 A medicação deve ser ingerida de acordo com a posologia previamente indicada, que varia ente 3 e 30 gotas diárias, conforme a doença e a gravidade de sua manifestação. Alguns cuidados com a conservação do medicamento também devem ser tomados: por se tratar de um produto natural, as "gotinhas" devem ser conservadas na parte inferior do refrigerador, numa temperatura média em torno dos 10 graus centígrados, acondicionadas em recipiente fechado e escuro para que não se alterem suas propriedades ativas. O medicamento deve ser ingerido várias horas antes da primeira refeição ou após a última refeição, sempre junto com azeite ou alguma outra substância oleosa. Nesse caso, a recomendação é preferencialmente o azeite, por se tratar de uma substância de preço acessível e com alto grau de pureza em sua composição. Os cuidados relativos à ingestão do medicamento, longe de serem "ritualísticos", são freqüentemente justificados como uma forma de potencializar a ação das "gotinhas" no organismo: o sistema digestivo deve estar vazio para que ocorra o melhor aproveitamento possível; o azeite, por sua vez, auxilia na absorção não apenas das "gotinhas", mas de qualquer 
medicamento fitoterápico.

17 Todo o trabalho desenvolvido na Fundação se encontra imbuído de um ideal de solidariedade e caridade, que se alimenta e se atualiza através dessa prestação de serviços. A instituição procura realizar um trabalho explicitamente filantrópico, onde todos recursos mobilizados a partir da venda de seus produtos passam a ser reutilizados na fabricação das "gotinhas", que são gratuitas e distribuídas indistintamente ao público em geral.

18 Nota-se, nesse espaço alternativo, a ausência de um horizonte comum de expectativas, compartilhado entre os terapeutas e a clientela. Embora a grande maioria dos doentes que chegam à Fundação já tenha experimentado todos os recursos terapêuticos de tratamento do câncer desenvolvidos pela medicina - configurando uma população majoritariamente composta por "doentes terminais" -, o tratamento ali oferecido não se insere numa lógica de "tentativa derradeira", como uma boa parcela dos doentes costuma acreditar.

19 A composição fitoterápica do medicamento é fruto de uma experiência estática vivenciada por dona Conceição, nos moldes de uma "revelação". Dona Conceição não discute o caráter religioso dessa experiência.

20 A acusação de exercício ilegal da medicina, para dona Conceição, incide sobre a terapêutica que articula procedimento diagnóstico e de intervenção e tratamento. Na medida em que o diagnóstico trazido por seus pacientes é "oficial", ela não se reconhece como praticante de uma medicina "ilegal".

21 O termo "alternativo", aqui utilizado, é sempre referido às características que norteiam a rede terapêutica alternativa. 
The Diversity of the Alternative Therapy Network in Rio de Janeiro

This article discusses the different concepts of therapeutic practices that emerge from the diffuse notions of "holistic cure" and "energy", characteristics of what are referred to as alternative or "New Age" therapies. Two unique and contrasting therapeutic experiences are analyzed, expressing the differentiation within what I designate as the "alternative therapy network". The cases presented here are indicative of the difficulties in establishing a rigid demarcation between different alternative therapies, thus highlighting the possible areas for links between "New Age" and local therapeutic religious culture.

Keywords: Religion; New Age movement; alternative therapies.

Recebido em: 11/04/2002.

Aprovado em: 09/10/2002. 